\title{
Outbreak of diarrhoea among participants of a triathlon and a duathlon on 12 July 2015 in Utrecht, the Netherlands
}

\author{
S. PARKKALI ${ }^{1,2} *$ R. JOOSTEN ${ }^{3}$, E. FANOY $^{1,3}$, R. PIJNACKER $^{1,2}$, \\ J. VAN BEEK ${ }^{1,4}$, D. BRANDWAGT ${ }^{3}$ AND W. VAN PELT ${ }^{1}$ \\ ${ }^{1}$ Centre for Infectious Diseases, Epidemiology and Surveillance, National Institute for Public Health and the \\ Environment (RIVM), Bilthoven, The Netherlands \\ ${ }^{2}$ European Programme for Intervention Epidemiology Training (EPIET), European Centre for Disease \\ Prevention and Control (ECDC), Stockholm, Sweden \\ ${ }^{3}$ Public Health Service Region Utrecht, Zeist, The Netherlands \\ ${ }^{4}$ Department of Viroscience, Erasmus MC, Rotterdam, The Netherlands
}

Received 3 November 2016; Final revision 19 April 2017; Accepted 19 April 2017; first published online 17 May 2017

\section{SUMMARY}

On 12 July 2015, a triathlon competition with 900 participants took place in Utrecht, the Netherlands. An outbreak investigation was initiated after 56 participants reported health complaints. An online questionnaire was sent to 700 participants. Stool specimens from six participants and four water specimens were collected from the swimming location. A total of 239 participants completed the questionnaire (response rate: $34 \%), 73(31 \%)$ of them met the case definition for acute gastrointestinal illness (AGI). A total of $67 \%$ of the respondents were male and the median age was 38 years. Almost half $(42 \%)$ of swimmers reported health complaints. Consumption of energy drinks and ingesting $\geqslant 3$ mouthfuls of canal water were identified as risk factors for AGI among swimmers only (adjusted relative risks (aRR) 1.6; 95\% confidence intervals (CI) 1.0-2.5 and aRR 2.6; 95\% CI 1.5-4.8). The collected water specimens tested positive for norovirus genogroup I and rotavirus and stool specimens tested positive for norovirus genogroup II. Our findings indicate that the outbreak could have been caused by exposure to norovirus during swimming. Swimmers should get information about the health risks for making an informed choice about participating. For future events, the organisers decided to change the swimming location from a canal to a recreational lake.

Key words: Gastrointestinal disease, norovirus, outbreak, swimming, triathlon.

\section{INTRODUCTION}

Swimming events in urban canals have become increasingly popular in the Netherlands. All sorts of multi-sport events can include swimming in canal water, such as triathlons, obstacle races and mud races.

\footnotetext{
* Author for correspondence: S. Parkkali, National Institute for Public Health and the Environment, PO Box 1, 3720 BA Bilthoven, the Netherlands.

(Email: saara.parkkali@gmail.com)
}

The Public Health Services (PHS) in the Netherlands do not have evidence-based guidelines for preventive measures that should be taken in urban swimming events to protect the health of swimmers. Identifying the risk factors for the development of health complaints after this type of swimming event can help develop recommendations that will prevent outbreaks at future events.

The canals in the Netherlands are exposed to various sources of contamination such as overflow of sewage after heavy rains and run-off of manure from agricultural land [1]. A study in the Netherlands compared 
the water quality of recreational lakes and nonrecreational canals in Amsterdam between 2003 and 2005. The water quality in the recreational lakes was found to be excellent, based on the European Bathing Water Directive, but poor in the canals [2]. Viral pathogens such as norovirus, rotavirus, and enterovirus were detected in canal water. This indicates that exposure to the water in Amsterdam canals could cause health risks [3]. A study on waterborne disease outbreaks during 1991-2007 in the Netherlands showed an association between exposure to untreated recreational waters, skin problems and acute gastrointestinal illness (AGI). Even when the official bathing water quality was compliant with European bathing water legislation, outbreaks of skin conditions and AGI have been reported [4].

Health risks associated with swimming in recreational waters were investigated in a Dutch prospective cohort study of seven triathlons and 15 duathlons between 1993 and 1994 [5]. Compared with nonswimmers, swimmers had a significantly increased risk of developing AGI in the week after swimming. In Denmark, two retrospective cohort studies after the triathlon events in 2010 and 2011 found that unintentionally swallowing contaminated seawater while swimming increased the risk of illness and the risk was further increased with the number of mouthfuls of seawater swallowed [6].

On 12 July 2015, a triathlon event took place in Utrecht with 900 participants. The participants of the event could compete in a triathlon (swim-bike-run) or a duathlon (run-bike-run) competition. The swimming competition took place in two locations: a harbour (Veilinghaven) near Utrecht City Centre and in a canal connected with the harbour (Merwedekanaal). Participants could choose to swim 500, 1000 or $1500 \mathrm{~m}$. Fifty-six participants reported AGI to the PHS 2 days after the event. The public health authorities initiated a study to assess the magnitude of the outbreak, identify the source and determine the risk factors for becoming ill, as well as develop public health recommendations. An investigation was initiated in cooperation with the PHS and the National Institute for Public Health and the Environment (RIVM). In this paper, we describe this outbreak investigation that took place after the triathlon and duathlon event in July 2015 in Utrecht.

\section{METHODS}

A retrospective cohort study was conducted among participants of the triathlon and duathlon participants. A case was defined as a participant of the event on 12 July 2015 with AGI, including at least one of the following complaints: vomiting, diarrhoea, nausea and/or stomach pain that started within 7 days of the end of the triathlon or duathlon.

Two days after the event, the organiser reported to the PHS that they were approached by 56 participants who self-reported health complaints such as nausea, vomiting and diarrhoea. Explorative telephone interviews with seven participants were used to develop an online questionnaire to identify exposure. Participants reported that organisers served free, precut fruit (orange, banana and watermelon) and energy drinks. The fruit was prepared and served by volunteers and the energy drinks were diluted from concentrate and served from jerry cans by volunteers.

Information on the food and drinks that were served was collected from the organisers of the event. The PHS designed a questionnaire to collect information on symptoms and exposures. Information was gathered on socio-demographic characteristics, swimmingrelated exposures (i.e. swimming technique, duration, distance and average number of mouthfuls of swallowed water while swimming), detailed information on health complaints, the use of catering, the use of toilets or showers after or during the event, specific information on the participants' dietary habits and the use of food supplements. We categorised responses based on the literature (e.g. mouthfuls of water, body mass index (BMI)), or were arbitrarily chosen (age distribution). The distance categories were based upon the actual distances swam. The event organiser sent a questionnaire link to the event participants by email. The questionnaire was sent to 700/900 participants for whom an email address was available, and was accessible from 17 July to 21 July 2015. A NetQ questionnaire tool was used. The data was analysed jointly by the PHS and RIVM.

\section{Statistical analysis}

Relative risks (RR) with corresponding 95\% confidence intervals $(\mathrm{CI})$ were calculated using binominal regression models for the association between having AGI and independent variables, such as consumption of different food items at the event, the use of common toilets and showers, swimming-related factors and the use of medicines or supplements. Variables with a $P$-value $<0 \cdot 2$ were selected for inclusion in the multivariable models and those with a $P$-value of $<0.05$ were retained. We fitted two multivariable 
regression models, one for swimmers and nonswimmers together and another one for only swimmers. The multivariable models were built using backward selection. Age and gender were included in the model. When removal of variables changed the coefficients of other variables by $>10 \%$, the variable was retained in the model as a confounder, regardless of significance. Statistical analyses were performed using Stata, Version 13 software.

\section{Laboratory and environmental investigation}

A regional water board in Utrecht (de Stichtse Rijnlanden) performs regular screening of water specimens. The PHS collected water specimens at the swimming location 8 days after the event from the harbour and at three points along the route, in the harbour at the start and the end, and half way along the route. Stool specimens from symptomatic participants were collected and tested for viral (e.g. norovirus, rotavirus, adenovirus and sapovirus) and bacterial agents (e.g. Salmonella, Shigella, Campylobacter and Yersinia). Samples were further characterised by sequence analysis. The air temperature measured at a nearby weather station (De Bilt) for the month of July was examined, as well as the canal water temperatures during and before the event.

\section{RESULTS}

The questionnaire response rate was 34\% (239/700) (Fig. 1). The median age of the respondents was 38 years (range 15-67) and $159(67 \%)$ were male. A total of $73(31 \%)$ of the respondents met the AGI case definition. The attack rate of AGI among swimmers $(33 \%, 72 / 215)$ was higher than among nonswimmers $(4 \%, 1 / 24)$. Nine cases had symptom onset on the day of the event, 61 developed symptoms during the 2 days after the event and the peak of the outbreak was on 13 July in the afternoon. The epidemic curve (Fig. 2) indicates a point source outbreak.

In total, 90\% (215/239) of the respondents swam and $38 \% \quad(n=91)$ reported health complaints. Among the AGI cases, 99\% (72) swam and one case did not. The most frequently reported complaints among the AGI cases were: stomach pain $(71 \%, 52 /$ $73)$, nausea $(77 \%, 56 / 73)$, diarrhoea $(59 \%, 43 / 73)$, vomiting $(38 \%, 28 / 73)$ and fever $(23 \%, 17 / 73)$. Among all respondents, other health complaints mentioned were headache ( $n=37,36$ swimmers), muscle or joint pain ( $n=34$, all swimmers), shivering

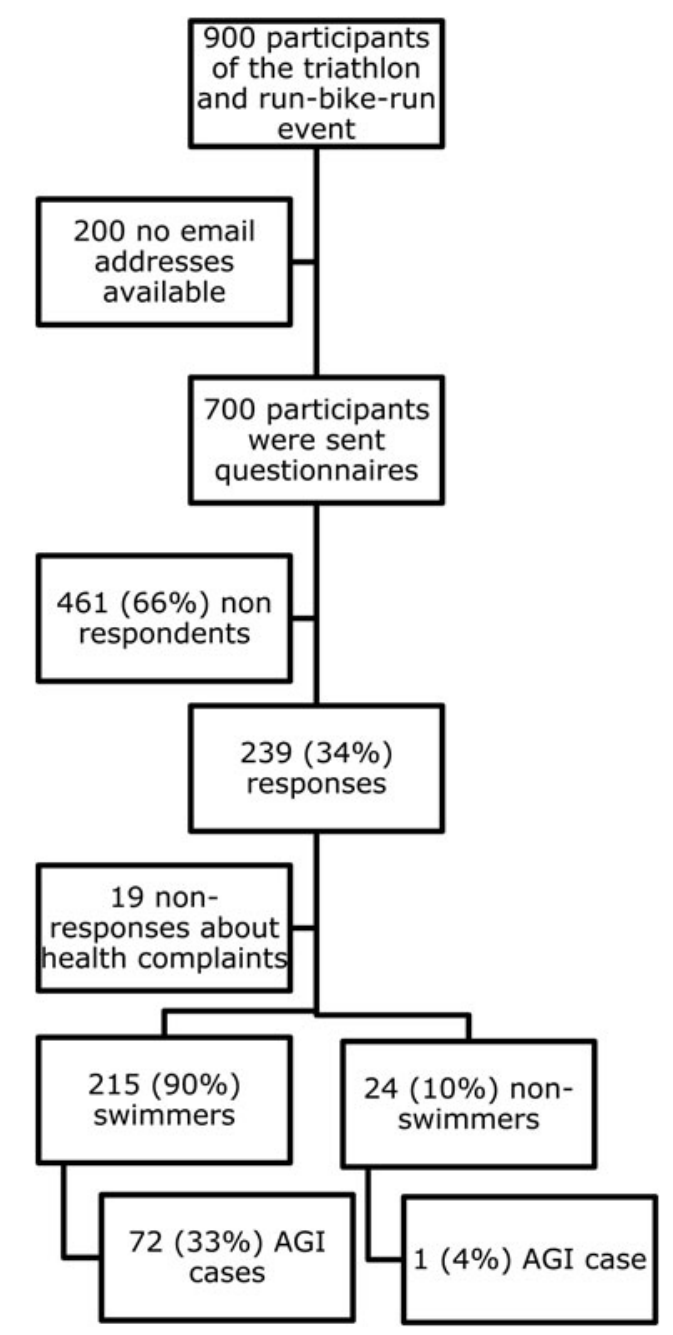

Fig. 1. Flow chart of study participants.

( $n=20$, all swimmers), respiratory symptoms $(n=6$, all swimmers), red eyes ( $n=2$, all swimmers) or skin complaints ( $n=1$, one swimmer). One hundred and two respondents $(43 \%)$ mentioned swimming in another open-water source in the week before the triathlon (cases $n=37$, non-cases $n=65$ ). Seven cases visited a doctor because of the health complaints following the event. Characteristics among cases and non-cases among the triathlon and duathlon participants are presented in Table 1.

In the univariable analysis, female gender, swimming, swallowing water, energy drink consumption, using any medicines or antacids and swimming in open water in the week before the event were associated with becoming ill ( $P$-value $<0 \cdot 2$, Table 2$)$. In the first multivariable analysis among swimmers and non-swimmers, the risk of AGI was increased when they consumed free energy drinks (Table 3). In the second multivariable analysis among swimmers-only, 


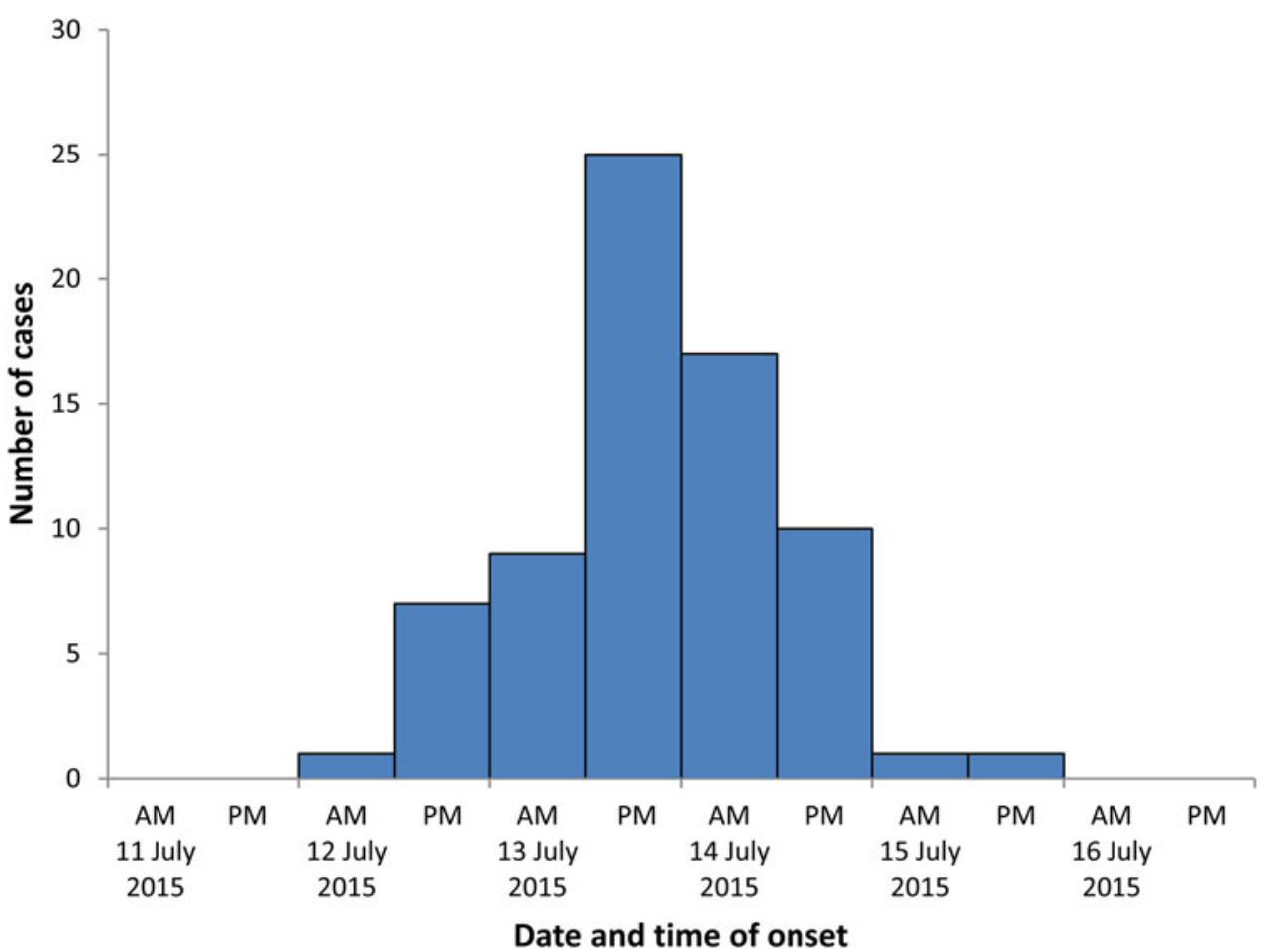

Fig. 2. Number of cases $(N=73)$ by date and time of AGI onset following the triathlon event on 12 July 2015 in Utrecht, the Netherlands. The time of onset is missing in one case who reported symptom onset on 12 July 2015.

the risk of AGI increased after consumption of energy drinks (adjusted RR (aRR) 1.6; 95\% CI 1.0-2.5), which was an independent predictor for illness. The mouthfuls of water swallowed showed an increased RR when comparing 1 to 2 mouthfuls and $\geqslant 3$ mouthfuls to no ingestion of water (aRR $1 \cdot 8 ; 95 \%$ CI $0 \cdot 9-3 \cdot 4$ and aRR 2.6; 95\% CI 1.5-4.8) (Table 4).

\section{Laboratory results}

Available stool specimens $(n=6)$ all tested positive for norovirus genogroup II (GII), of which four were norovirus GII.P4 New Orleans 2009 (polymerase) and one was GII.4 Sydney 2012 (capsid). Sequencing was unsuccessful in one stool sample. Routine water quality measurements from canals in Utrecht showed that Escherichia coli and intestinal enterococci levels were within normal limits in July. All four water specimens were PCR positive for norovirus genogroup I (GI) and for rotavirus.

\section{DISCUSSION AND CONCLUSIONS}

Following the triathlon and duathlon event on 12 July 2015 in Utrecht, 34\% (72/215) swimmers reported AGI versus $4 \%(1 / 24)$ non-swimmers. The main clinical symptoms were diarrhoea $(59 \%)$ and vomiting $(38 \%)$. The attack rate and the resolution of symptoms within 2 days suggested a viral origin, which was supported by the detection of norovirus in stool specimens as causal agent of the outbreak. Although numbers are small and the response rate was low, we assume a point source outbreak.

The increased risk of ingesting water and a doseresponse of mouthfuls of water swallowed indicated that swimming in open water was the most likely source of infection. Outbreaks of norovirus are common and faecal-oral transmission is the most common route for infection, such as ingestion of contaminated food, water or through (in)direct oral contact with a contaminated object $[7,8]$. In our study, none of the food items besides energy drinks were associated with AGI. Unfortunately, no food samples were available for microbiological analysis and vehicles for transmission such as contaminated door handles or toilet seats could not be investigated, as toilet and showering facilities had been removed from the location of the event. The event was mentioned in the local news, which could have encouraged more participants with health complaints to respond to the questionnaire compared with those without health complaints. Using a wide case definition could have 
Table 1. Characteristics among AGI cases $(n=73)$ and non-cases $(n=166)$ who participated as swimmer or non-swimmer following the triathlon event on 12 July 2015 Utrecht, Netherlands

\begin{tabular}{|c|c|c|c|c|}
\hline \multirow[b]{2}{*}{ Characteristic } & \multicolumn{2}{|c|}{ Case $N=73$} & \multicolumn{2}{|c|}{ Non-case $N=166$} \\
\hline & $n$ & $\%$ & $n$ & $\%$ \\
\hline \multicolumn{5}{|l|}{ Gender } \\
\hline Female & 29 & 40 & 51 & 31 \\
\hline Male & 44 & 60 & 115 & 69 \\
\hline Missing & - & - & - & - \\
\hline \multicolumn{5}{|l|}{ Age, in years } \\
\hline$<25$ & 7 & 10 & 15 & 9 \\
\hline $25-35$ & 28 & 38 & 54 & 33 \\
\hline$>35$ & 34 & 47 & 89 & 54 \\
\hline Missing & 4 & 5 & 8 & 5 \\
\hline \multicolumn{5}{|l|}{ BMI } \\
\hline Underweight & 2 & 3 & 1 & 1 \\
\hline Normal & 62 & 85 & 139 & 84 \\
\hline Overweight & 7 & 10 & 24 & 14 \\
\hline Obese & 0 & 0 & 1 & 1 \\
\hline Missing & 2 & 3 & 1 & 1 \\
\hline \multicolumn{5}{|l|}{ Swam in triathlon } \\
\hline Yes & 72 & 99 & 143 & 86 \\
\hline No & 1 & 1 & 23 & 14 \\
\hline Missing & - & - & - & - \\
\hline \multicolumn{5}{|l|}{ Distance swam (m) } \\
\hline 500 & 25 & 34 & 65 & 39 \\
\hline 1000 & 25 & 34 & 37 & 22 \\
\hline 1500 & 22 & 30 & 41 & 25 \\
\hline Missing & 1 & 1 & 23 & 14 \\
\hline \multicolumn{5}{|l|}{ Minutes swam } \\
\hline$\leqslant 15$ & 23 & 32 & 60 & 36 \\
\hline$>15$ & 45 & 62 & 65 & 39 \\
\hline Missing & 5 & 7 & 41 & 25 \\
\hline \multicolumn{5}{|l|}{ Swimming technique* } \\
\hline Freestyle & 66 & 90 & 127 & 77 \\
\hline Breast stroke & 21 & 29 & 40 & 24 \\
\hline \multicolumn{5}{|l|}{ Swallowed water } \\
\hline 0 mouthfuls & 13 & 18 & 57 & 34 \\
\hline $1-2$ mouthfuls & 22 & 30 & 43 & 26 \\
\hline 3 or more mouthfuls & 38 & 52 & 66 & 40 \\
\hline Missing & - & - & - & - \\
\hline \multicolumn{5}{|l|}{$\begin{array}{l}\text { Type of diet during past } \\
\text { month }\end{array}$} \\
\hline Meat and fish & 57 & 78 & 134 & 81 \\
\hline Meat, no fish & 9 & 12 & 18 & 11 \\
\hline Fish, no meat & 2 & 3 & 5 & 3 \\
\hline No fish, no meat & 5 & 7 & 7 & 4 \\
\hline Missing & - & - & 2 & 1 \\
\hline \multicolumn{5}{|l|}{ Reported using } \\
\hline Vitamins & 17 & 23 & 41 & 25 \\
\hline Protein supplements & 6 & 8 & 18 & 11 \\
\hline Mineral supplements & 5 & 7 & 17 & 10 \\
\hline Probiotics & 2 & 3 & 2 & 1 \\
\hline Any medicines in general & 18 & 25 & 22 & 13 \\
\hline Antacids & 2 & 3 & - & - \\
\hline \multicolumn{5}{|l|}{ Hours of sports/week } \\
\hline$<5 \mathrm{~h}$ & 30 & 41 & 69 & 42 \\
\hline$\geqslant 5 \mathrm{~h}$ & 43 & 59 & 97 & 58 \\
\hline Missing & - & - & - & - \\
\hline
\end{tabular}


Table 1 (cont.)

\begin{tabular}{|c|c|c|c|c|}
\hline \multirow[b]{2}{*}{$\begin{array}{l}\text { Used mobile toilet before, } \\
\text { during or after the event* }\end{array}$} & \multicolumn{2}{|c|}{ Case $N=73$} & \multicolumn{2}{|c|}{ Non-case $N=166$} \\
\hline & 51 & 70 & 105 & 63 \\
\hline Used shower after the event & 1 & 1 & 4 & 2 \\
\hline Missing & - & - & - & - \\
\hline Ate food from the restaurant & 12 & 16 & 25 & 15 \\
\hline Missing & - & - & - & - \\
\hline \multicolumn{5}{|l|}{$\begin{array}{l}\text { Consumed from the } \\
\text { organiser* }\end{array}$} \\
\hline Pre-mixed energy drink & 52 & 71 & 91 & 55 \\
\hline Water & 54 & 74 & 117 & 70 \\
\hline Watermelon pieces served & 26 & 36 & 68 & 41 \\
\hline \multicolumn{5}{|l|}{ from a tray } \\
\hline Orange served from a tray & 29 & 40 & 65 & 39 \\
\hline Banana served from a tray & 31 & 42 & 69 & 42 \\
\hline $\begin{array}{l}\text { Swam in open water in the } \\
\text { week before } \\
\text { the event }\end{array}$ & 37 & 51 & 65 & 39 \\
\hline Missing & - & - & - & - \\
\hline
\end{tabular}

* Swimmers could mention more than one option.

Table 2. Univariable risk ratios and corresponding $95 \%$ CI of factors associated with AGI (P-value <0·2) among swimmers and non-swimmers adjusted for age and gender

\begin{tabular}{|c|c|c|c|c|c|c|c|}
\hline \multirow[b]{2}{*}{ Risk factor (total respondents) } & \multicolumn{2}{|c|}{$\begin{array}{l}\text { Exposed to risk } \\
\text { factor }\end{array}$} & \multicolumn{2}{|c|}{$\begin{array}{l}\text { Unexposed to risk } \\
\text { factor }\end{array}$} & \multirow[b]{2}{*}{$\mathrm{RR}$} & \multirow[b]{2}{*}{$95 \% \mathrm{CI}$} & \multirow[b]{2}{*}{$P$-value } \\
\hline & Total & Cases $(\%)$ & Total & Cases $(\%)$ & & & \\
\hline Swallowed water while swimming $(n=215)$ & 145 & $59(41)$ & 70 & $13(19)$ & $2 \cdot 2$ & $1 \cdot 3-3 \cdot 7$ & $0 \cdot 001$ \\
\hline Swam in the event $(n=239)$ & 215 & $72(34)$ & 24 & $1(4)$ & $8 \cdot 0$ & $1 \cdot 2-55 \cdot 3$ & 0.003 \\
\hline Consumed free energy drink $(n=239)$ & 143 & $52(36)$ & 96 & $21(22)$ & $1 \cdot 7$ & $1 \cdot 1-2 \cdot 6$ & $0 \cdot 017$ \\
\hline Used medicines $(n=239)$ & 40 & $18(45)$ & 199 & $55(28)$ & $1 \cdot 6$ & $1 \cdot 1-2 \cdot 5$ & 0.030 \\
\hline Swam in open water in week before the event $(n=239)$ & 102 & $37(36)$ & 137 & $36(26)$ & $1 \cdot 4$ & $0 \cdot 9-2 \cdot 0$ & $0 \cdot 100$ \\
\hline Used antacids $(n=40)$ & 2 & $2(100)$ & 38 & $16(42)$ & $2 \cdot 4$ & $1 \cdot 6-3 \cdot 4$ & $0 \cdot 109$ \\
\hline Being male $(n=239)$ & 159 & $44(28)$ & 80 & $29(36)$ & $0 \cdot 8$ & $0 \cdot 5-1 \cdot 1$ & $0 \cdot 174$ \\
\hline
\end{tabular}

overestimated the number of cases. The questionnaire was accessible between 5 and 9 days after the event, and recall bias on specific risk factors could have occurred (i.e. number of mouthfuls of water swallowed, swimming technique used and consumption of food and drinks).

The risk of illness increased when swimmers ingested more than 3 mouthfuls of water. Other studies have reported comparable findings, where a higher number of mouthfuls of water swallowed was associated with increased risk of illness [5, 6, 9-11]. Our study found that the duration of swimming (i.e. increased duration of exposure) and swimming distance was not significantly independently associated with AGI. This could be an indicator for a contaminated area, such as at the start or the end of the swimming route at the harbour where all swimmers, regardless of swimming distance or duration, passed through when getting in or out of the water.

Faecal contamination of surface waters has been known to occur after heavy rain due to sewage overflow and after discharge of untreated sewage [3]. However, no heavy rains were reported in Utrecht before the event. Regular screening of the canal water for faecal indicator bacteria (E. coli and intestinal enterococci) was performed in Utrecht. The 
Table 3. Multivariable risk ratios and corresponding 95\% CI of the factors associated with AGI among swimmers and non-swimmers

\begin{tabular}{lll}
\hline \hline & Risk ratio $(95 \% \mathrm{CI})$ & $P$-value \\
\hline $\begin{array}{l}\text { Gender } \\
\text { Male }\end{array}$ & $0 \cdot 7(0 \cdot 5-1 \cdot 1)$ & $0 \cdot 115$ \\
$\quad$ Female & Reference & - \\
Age & & \\
$\quad<25$ & Reference & - \\
$25-35$ & $1 \cdot 2(0 \cdot 6-2 \cdot 4)$ & $0 \cdot 618$ \\
$>35$ & $1 \cdot 0(0 \cdot 5-2 \cdot 0)$ & 0.963 \\
Consumed free energy drink & $1 \cdot 8(1 \cdot 1-2 \cdot 8)$ & $0 \cdot 013$ \\
\hline \hline
\end{tabular}

Table 4. Multivariable risk ratios and corresponding 95\% CI of the factors associated with AGI among swimmers

\begin{tabular}{lll}
\hline \hline & Risk ratio $(95 \% \mathrm{CI})$ & $P$-value \\
\hline $\begin{array}{l}\text { Gender } \\
\text { Female }\end{array}$ & Reference & - \\
$\quad$ Male & $0 \cdot 8(0 \cdot 6-1 \cdot 1)$ & $0 \cdot 191$ \\
Age & & \\
$\quad<25$ & Reference & - \\
$25-35$ & $0 \cdot 8(0 \cdot 5-1 \cdot 6)$ & $0 \cdot 626$ \\
$>35$ & $0 \cdot 7(0 \cdot 4-1 \cdot 3)$ & $0 \cdot 362$ \\
Consumed free energy drink & $1 \cdot 6(1 \cdot 0-2 \cdot 5)$ & $0 \cdot 039$ \\
Mouthfuls water swallowed & & \\
$\quad$ None & Reference & - \\
$1-2$ mouthfuls & $1 \cdot 8(0 \cdot 9-3 \cdot 4)$ & $0 \cdot 073$ \\
$\geqslant 3$ mouthfuls & $2 \cdot 6(1 \cdot 5-4 \cdot 8)$ & $0 \cdot 001$ \\
Minutes swam & & \\
$\quad \leqslant 15$ & Reference & - \\
$>15$ & $1 \cdot 6(0 \cdot 9-2 \cdot 1)$ & $0 \cdot 093$ \\
\hline \hline
\end{tabular}

routine water quality measurements from the canals in Utrecht showed that $E$. coli and intestinal enterococci levels were within normal limits in July (personal communication from Hoogheemraadschap Stichtse Rijnlanden, July, 2016). However, the levels of faecal indicator bacteria do not always correspond with the presence of other potentially harmful organisms, such as viruses [4, 12]. Many outbreaks of norovirus associated with recreational waters have been described in the literature $[11,13,14]$. Norovirus has been reported to be persistent in the environment; in groundwater it was found to be infectious for humans after 2 months and norovirus RNA was detectable even after 588 days [8]. It has been suggested that GI is less stable on surfaces and more stable in water compared with GII strains $[15,16]$.
Previous studies have found that the number of norovirus outbreaks in summer is positively correlated with the preceding number of days with a maximum air temperature of $25^{\circ} \mathrm{C}[4,17]$. The average air temperature measured at the nearby De Bilt weather station for July 2015 was $18.4{ }^{\circ} \mathrm{C}$. Air temperatures exceeding $25^{\circ} \mathrm{C}$ were not reported in the days before the event. On the day of the event, the average air temperature was $17 \cdot 7^{\circ} \mathrm{C}$ [18]. The routinely measured temperatures of the canal water in Utrecht were higher than normal during the summer of 2015 . The average canal water temperature was $21.3{ }^{\circ} \mathrm{C}$ in July and $21.7{ }^{\circ} \mathrm{C}$ on 12 July (Hoogheemraadschap Stichtse Rijnlanden, personal communication, July 2016). These water temperatures could have facilitated the outbreak but norovirus is more commonly found in surface waters when the water temperature is higher [17].

The risk of AGI was higher among those who consumed energy drinks. No energy drink was available for laboratory testing. The energy drink was premixed from a concentrate, diluted with tap water, and served free-of-charge to participants from jerry cans by the volunteers. None of the energy drink handlers reported AGI complaints. Based on the analysis, we assume, but cannot rule out, that the energy drink was not a norovirus source. Furthermore, to our knowledge, no study has reported that presence of energy drink in the gut environment could be a risk factor for norovirus infection or AGI in general. However, a literature review on adverse and beneficial effects on consumption of energy drinks reported gastrointestinal and metabolic adverse effects. The study suggests that the high-sugar content in energy drinks may reduce the activity, diversity and gene expression of intestinal bacteria [19]. Although the relationship between illness and the consumption of energy drinks could be influenced by a confounding factor, this finding is interesting and will be explored further in future studies. Energy drink consumption may subsequently have increased the risk for developing AGI, regardless of its possible contamination with norovirus. The mechanism for added risk of drinking certain beverages such as energy drinks shortly before physical exercise is not clear, but may play a role. In our study, the risk among females was not significantly higher than among males, but has been reported to be higher in another study on AGI among triathletes in Denmark [6]. Other studies have reported that different genders report and express symptoms differently [20, 21].

Norovirus belonging to genogroups GI and GII are the most common viruses causing gastroenteritis in 
humans among all age groups [22]. Food and waterborne outbreaks have been associated with GI and GII strains and waterborne outbreaks have been more commonly associated with only GI strains [8]. In our study, six stool specimens were positive for norovirus GII, of which four specimens had the same genotype and variant GII.4. They did not match with the norovirus GI that was detected in the water specimens. It is possible that norovirus GII was also present in the water but was not detected in the sampled water. Alternatively, if norovirus GI was ingested by swimmers, it did not replicate sufficiently to cause disease or be detected in stool due to the detection limit of the assay. It is also possible that norovirus GI was present in the stool of a participant for whom no stool specimens was available or contamination appeared with food or energy drink consumption of which no specimens were available to test. The water specimens collected in our study did not meet the recommended amount of water for testing [3]. Because water specimens were collected 1 week after the event, it is possible that norovirus GII was present in the water at the time of the event as water quality in the canals is subject to frequent change. Specimens taken in advance or after the event may not be a good indication of faecal contamination. The routine collecting of water samples for checking for faecal indicator bacteria from unofficial bathing waters is probably not sufficient to predict the risk of viral infections.

\section{Actions and recommendations}

The PHS informed the municipality and the event organiser of the results of the investigation in a press release on their website. The participants of the event were informed about the results of the investigation through the event organiser. The PHS repeated previous information to them about the possible risk of contracting illness when exposed to canal water. The event organisers were informed about the various means of norovirus transmission, possible risks when handling and serving pre-cut fruit or drinks from a common container. Because our study found increased risk by ingesting water while swimming, swimmers should be informed about the increased risk for AGI. Providing such information for participants will assist them in making an informed choice about their participation in similar events in the future. Event organisers should discuss health and safety issues with the PHS before the events. The PHS can test the water before any event for both coliform bacteria and noroviruses and can follow up on health complaints after such an event, to evaluate the adequacy of the preventive measures taken. In 2016, the event organisers of the annual Utrecht triathlon changed the swimming location to a location with official recreational water. No outbreak was notified afterwards.

\section{ACKNOWLEDGEMENTS}

The authors would like to thank colleagues at the RIVM, Sint Antonius Hospital and the GGD region Utrecht, for their advice, experience and all their help with the analysis. They are grateful to Rob van de Kamp from Hoogheemraadschap Stichtse Rijnlanden for providing information about canal water quality and temperature measurements of canal waters in Utrecht. They would like to thank the organiser of the Rijwielpaleis Bilthoven Triathlon for this study opportunity. They would also like to thank EPIET Supervisor, Susan Hahné and EPIET Coordinator, Christian Winter for their advice and comments on the research.

\section{REFERENCES}

1. Pruss A. Review of epidemiological studies on health effects from exposure to recreational water. International Journal of Epidemiology 1998; 27(1): 1-9.

2. Anonymous. Directive 2006/7/EC of the European Parliament and of the Council of 15 February 2006 concerning the management of bathing water quality and repealing directive 76/160EEC. Official Journal of European Union 2006; L64: 37-51.

3. Schets FM, et al. Monitoring of waterborne pathogens in surface waters in Amsterdam, the Netherlands, and the potential health risk associated with exposure to cryptosporidium and giardia in these waters. Applied and Environmental Microbiology 2008; 74(7): 2069-2078.

4. Schets FM, et al. Disease outbreaks associated with untreated recreational water use. Epidemiology and Infection 2011; 139(7): 1114-1125.

5. van Asperen IA, et al. Risk of gastroenteritis among triathletes in relation to faecal pollution of fresh waters. International Journal of Epidemiology 1998; 27(2): 309-315.

6. Harder-Lauridsen NM, et al. Gastrointestinal illness among triathletes swimming in non-polluted versus polluted seawater affected by heavy rainfall, Denmark, 2010-2011. PLoS ONE 2013; 8(11): e78371.

7. Bitler EJ, et al. Norovirus outbreaks: a systematic review of commonly implicated transmission routes and vehicles. Epidemiology and Infection 2013; 141(8): 1563-1571.

8. Matthews JE, et al. The epidemiology of published norovirus outbreaks: a review of risk factors associated with attack rate and genogroup. Epidemiology and Infection 2012; 140(7): 1161-1172. 
9. Schijven J, et al. A survey of diving behaviour and accidental water ingestion among Dutch occupational and sport divers to assess the risk of infection with waterborne pathogenic microorganisms. Environmental Health Perspectives 2006; 114(5): 712-717.

10. Public Health England. Epidemiological investigation into gastrointestinal illness following public swimming in the River Thames, London October 2012·2013; Public Health England (https://www.gov.uk/government/publications/gastrointestinal-illness-outbreak-investigation-following-a-mass-participation-river-thames-swim).

11. Sartorius B, et al. Outbreak of norovirus in Vastra Gotaland associated with recreational activities at two lakes during August 2004. Scandinavian Journal of Infectious Diseases 2007; 39(4): 323-331.

12. Arnold BF, et al. Swimmer illness associated with marine water exposure and water quality indicators: impact of widely used assumptions. Epidemiology (Cambridge, Mass) 2013; 24(6): 845-853.

13. Zlot A, et al. Norovirus outbreak associated with a natural lake used for recreation - Oregon, 2014. MMWR Morbidity and Mortality Weekly Report 2015; 64(18): 485-490.

14. Wyn-Jones AP, et al. Surveillance of adenoviruses and noroviruses in European recreational waters. Water Research 2011; 45(3): 1025-1038.
15. Liu P, et al. Persistence of human noroviruses on food preparation surfaces and human hands. Food and Environmental Virology 2009; (1): 141-147.

16. Seitz SR, et al. Norovirus infectivity in humans and persistence in water. Applied and Environmental Microbiology 2011; 77(19): 6884-6888.

17. Schets FM, et al. Infections following recreational activities in lakes, rivers and canals: present and future risks of transmission in the Netherlands. Nederlands Tijdschrift voor Geneeskunde 2014; 158: A7969.

18. Royal Netherlands Meteorological Institute (KNMI) https://data.knmi.nl.

19. Alsunni AA. Energy drink consumption: beneficial and adverse health effects. International Journal of Health Sciences (Qassim) 2015; 9(4): 468-474.

20. Ladwig KH, et al. Gender differences of symptom reporting and medical health care utilization in the German population. European Journal of Epidemiology 2000; 16(6): 511-518.

21. Barsky AJ, et al. Somatic symptom reporting in women and men. Journal of General Internal Medicine 2001; 16 (4): 266-275.

22. Grondahl-Rosado RC, et al. A one year study on the concentrations of norovirus and enteric adenoviruses in wastewater and a surface drinking water source in Norway. Food Environmental Virology 2014; 6(4): 232-245. 